\title{
DISCUSSION
}

\section{Caste-washing the healthcare discriminatory practices \\ system will do little to address its}

\author{
SYLVIA KARPAGAM
}

\begin{abstract}
Bullying, discrimination and harassment within the healthcare system in India is well known and urgent measures have to be put in place to address them. However locating caste-based harassment as general bullying would be a disservice to the thousands of young people from vulnerable communities who often face extreme harassment within the system. Naming this as caste based harassment would be the first step to addressing it. There is an urgent need for reservation policies to be strengthened to allow representation of vulnerable communities at all levels of healthcare planning, implementation and evaluation.
\end{abstract}

Keywords: workplace bullying, caste, reservations, healthcare,

Barua MP and Verma A, in their article titled "Workplace bullying in healthcare facilities: Role of caste and reservation' (1), published in $I J M E$, perform the usual caste washing that is, in fact, a barrier to improving the healthcare system. Throughout the article, the authors tiptoe around caste as though some cases of abuse or harassment happen in society at large, and which they condemn, but which somehow magically don't exist within the Indian healthcare system. They conveniently conclude that bullying is an intrinsic part of the healthcare system and therefore shouldn't be attributed to "casteist innuendo". This is actually the usual clichéd manner in which caste-based bullying and harassment are explained away by people from oppressor communities.

Within the specific context of the case of Dr Payal Tadvi, the authors, while cleverly locating caste as a serious issue, also, locate the accused and her harassers as victims themselves they are all equally part of a larger system where doctors are generally harassed.

Focussing attention only on casteism tends to overshadow

Authors: Sylvia Karpagam (sakie339@gmail.com) Public health doctor and Researcher, Bengaluru, Karnataka, 560 047, INDIA.

To cite: Karpagam S. Caste-washing the healthcare system will do little to address its discriminatory practices. Indian J Med Ethics. 2021 Jan-Mar; 6(1) NS: 47-48. 2020.DOI:10.20529/IJME.2020.108.

Published online first on October 30, 2020

Manuscript Editor: Rakhi Ghoshal

(C) Indian Journal of Medical Ethics 2020 the bullying of doctors and medical students by their senior colleagues at the workplace. (1)

The unspoken question that is actually being asked here is "Why couldn't Dr Payal Tadvi just take harassment like everyone else does? Why does her harassment have to be categorised as caste based, when all of us face harassment?" This is the crux of the lack of empathy towards marginalised communities when they complain of workplace harassment or bullying. The harassment they face is seen as their own problem and due to their own inability to cope. The statement "unprofessional behaviour is an occupational hazard rather than an offence" implies that people who get into medicine have no business committing suicide because harassment is a "part of the job" - take it or leave it, but don't complain about it!

It is true that medical education is hierarchical and colonial. Junior doctors and other healthcare staff get a bad deal. Long hours, humiliation by professors, bad marks etc, are often projected as "normal" labour pangs of coming out as a fullfledged doctor. All doctors feel that they had a "tough" time getting their degrees; at the end of which, they feel justifiably proud of their resilience and determination. So when a colleague or a fellow student claims to have faced discrimination as though it is different and more than what everyone else is going through, people feel resentful.

It is therefore important, at this point, to understand whether the experience of discrimination or harassment or bullying is an incident/event, or part of a systemic process. A person from a marginalised community is unlikely to respond to one or two events or incidents of discrimination, because that is indeed what happens to everyone. However what really breaks or deeply damages a person is the experience of multiple levels of discrimination from multiple systems in a sustained and concerted manner. If one person in a team of ten mocks you for your communication skills, you may be able to ignore that person. But if eight out of ten mock you, and the other two keep quiet, then it's a different experience. Of course most people have experienced the first situation but they fail to understand the damaging effect of the second situation. The first experience may make you angry, irritated or sad. But the second is what is likely to push one to suicide, to dropping out of a hard-earned course, to changing one's personality. These 
changes can then be used to further mock, marginalise and victimise a person (2).

In the same example, when one person mocks you, you can seek support and possibly also receive it, from the other nine. If, even a few of the nine are in power, they can step in to control the person mocking you. But if the nine are not on your side, and if some of them hold power, and abuse it to further target you, then you become a victim of a system or structure. Any harassment that those bullying Payal Tadvi would have faced in the health system would have been isolated incidents, and they would have had recourse to addressing this, but the harassment that Dr Payal faced was structural (3).

The health system will necessarily reflect what is present in the larger society, unless there are clear checks and balances to address it. In Dr Payal's case, she had no grievance redressal system or anti-harassment/bullying committee or mentor to whom she could take her concerns. The absence of systems to keep caste discrimination in check is itself proof that caste discrimination exists because, as the authors themselves succinctly acknowledge - "The impact of caste in India is overwhelming."

The authors also say "While it is unconstitutional for doctors to indulge in biased behaviour towards fellow doctors belonging to SC/ST/OBC, at the same time doctors from SC/ $\mathrm{ST} / \mathrm{OBC}$ must understand that they have a greater responsibility of representing their communities in services and must resist yielding to adverse interpersonal dynamics."(1) This oft repeated equalisation of the responsibilities of the oppressor and oppressed has to be challenged head on. This attitude typically places equal onus on the oppressed for not "resisting oppression".

Expecting people from oppressed communities to "think of their communities" even as they are being oppressed is cruel. Oppression is a problem of the oppressors. They need to do something about it. If the health system and its inhabitants are not inclusive and are discriminatory, the health system needs to address it. The system cannot say "We will continue to be discriminatory. It is up to you to be brave and handle it. Think of your community!!" This is the advice thousands and thousands of people who are targeted and harassed every day hear. It is like a woman who is facing sexual harassment being given advice on everything ranging from her body language to her hairstyle to her voice to her clothes. Even if she followed every bit of advice of every person who gave it to her, she would still be no more or less vulnerable to sexual harassment. This is the same with caste. Unless the perpetrator changes, the problem will not even be acknowledged, leave alone addressed.

The authors also casually acknowledge that there are "doctors disapproving of reservation policies" who think of those entering post-graduation through reservation as "undeserving". Then they bypass this observation as though this disapproving and condescending attitude has no real consequences within the system. How do doctors who intrinsically believe that some of their colleagues or students are inferior put this attitude into practice? Will there not be everyday overt and covert ways to show this disdain? How are their colleagues/students from marginalised communities expected to react to this everyday harassment? By thinking of some larger good? Is it possible to think of a larger good when your dignity is being pulled down every day?

It is vital to have representation from marginalised communities at all levels of the healthcare system from policymaking, administration, management, clinical work, nursing, as one way of making the health system more responsive to larger social issues. The decision to have additional coaching classes, effective and functional grievance redressal mechanisms, mentorship programmes, language improvement skills, common eating systems, etc, will not come from communities that see no value in these interventions.

If healthcare providers themselves carry deep-rooted cultural, gender, caste and religious prejudices and biases, these can be damaging to the wellbeing of their patients as well as students and colleagues. They are incompetent to teach or practice patient care (4).

In the case of Dr Payal Tadvi, the deeper question is not really whether the accused should be punished or not. It is - What allowed them to behave that way? What is it about their families, their upbringing, their social ocations, their communities, their friends, their relatives, their teachers, the hospital management that allows a Payal Tadvi to be harassed so much that she commits suicide?

It is these structural enablers that have to be pulled out from the roots by the healthcare system, the education system and society at large. The excuse can no longer be "Oh, but there is bullying everywhere". The sooner this is acknowledged, the sooner it can be addressed, so that the Payal Tadvis of the country, from communities that desperately and urgently need representation, find their legitimate and dignified place as essential healthcare providers rather than being pushed into suicide.

\section{References}

1. Barua MP, Verma A. Workplace bullying in healthcare facilities. Role of caste and reservation. Indian J Med Ethics. Published online first on October 30, 2020. DOI: 10.20529/IJME.2020.106.

2. Karpagam S. More stardust; Dr Payal Tadvi was killed by a heartless soulless system. Newsminute. 2020 Jun 10 [cited 2020 Oct 27]. Available from: https://www.thenewsminute.com/article/morestardust-dr- payal-tadvi-was-killed-heartless-soulless-system-103335

3. Khan F, Ojha S. Dr Payal Tadvi Case: Testimonies put senior doctors roles in spotlight.. Mid-day.com. 2019 Aug 1 [cited 2020 Oct 27]. Available from: https://www.mid-day.com/articles/dr-payal-tadvicase-testimonies- put-senior-doctors-roles-in-spotlight/21456183

4. Karpagam S, Senthalir S. Why Dalits and the under privileged in India have built-in barriers to accessing mental health care. New Indian Express - Edexlive. 2020 Oct 11[cited 2020 Oct 27]. Available from: https://www.edexlive.com/opinion/2020/oct/11/why-dalits-and-theunderprivileged-in-india-have-built-in-barriers-to-accessing-mentalhealth-care-15150.html 